\title{
Study on the Interaction of Algal Peptides on Virulence Factors of Helicobacter pylori: In Silico Approach
}

\author{
Davoodbasha MubarakAli ${ }^{1}$. Thirusangu Akshaya ${ }^{1} \cdot$ Raghunathan Sathya $^{1}$. \\ Navabshan Irfan'
}

Received: 30 July 2021 / Accepted: 8 October 2021 /

Published online: 11 November 2021

(c) The Author(s), under exclusive licence to Springer Science+Business Media, LLC, part of Springer Nature 2021

\begin{abstract}
In the Asian region, Helicobacter pylori infects about $80 \%$ populations, which is most leading cause of peptic ulcers, and it is an asymptomatic infection. Studies reported that the particular bacteria carry specific virulence factors that leads to severe complications. These virulence factors can be used as a drug targets to inhibit their growth and pathogenicity. Chronic infection with $H$. pylori virulence factors are CagA, VacA and HtrA positive strains the risk factor of gastric cancer. In this study, we aimed to study the antagonistic interaction pattern between the potential eight algal peptides against the virulence factors of $H$. pylori through in silico analysis intended to treat peptic ulcer and prevent the further complications such as cancer. The proteins of virulent factors are docked using C-Docker algorithm and calculated the bind energy of the complexes. The results showed that the peptide derived from a green alga, Tetradesmus sp. are active against the three virulent factors such as cag-A, vac-A, and Htr-A with multiple hydrogen, vdW, electrostatic interactions, and mild $\pi$-hydrophobic bindings with the libdock energy score for CagA, VacA and HtrA are 175.625, 158.603 and $89.397 \mathrm{kcal} / \mathrm{mol}$. These primes and the peptide lead to develop a better and potential inhibitors against $H$. pylori infection.
\end{abstract}

Keywords Antibacterial algal peptides; H. pylori $\cdot \operatorname{VacA} \cdot \operatorname{CagA} \cdot \mathrm{HtrA} \cdot$ Libdock

\section{Introduction}

H. pylori are more common in poorer nations because of the generally poor sanitation and hygiene conditions caused by poor socio-economic infrastructure. H. pylori are the main causative agent of peptic and gastric ulcers. It is a gram-negative, rod-shaped,

Davoodbasha MubarakAli

mubinano@gmail.com

1 School of Life Sciences, B.S. Abdur Rahman Crescent Institute of Science and Technology, Chennai, Tamil Nadu, India

2 Crescent School of Pharmacy, B.S. Abdur Rahman Crescent Institute of Science and Technology, Chennai, Tamil Nadu, India 
microaerophilic, flagellated bacterium that causes stomach inflammation in more than half of the population; however, the affected individuals are asymptomatic. So this bacterium can enter our bodies and reside in the digestive tract. They cause sores called ulcers which may lead to cancer [1]. The World Health Organization (WHO) and the International Agency for Research on Cancer (IARC) have designated $H$. pylori as a class I carcinogen linked to the development of gastric cancer (GC) since 1994 [2].

Ulcers are the deep lesions penetrating through the entire thickness of the gastrointestinal tract that also lead to cancer because the stomach has a layer of mucus that is designed to protect from stomach acid. H. pylori attack this mucus lining and few part of the stomach exposed to acid together with the bacteria, and the acid can irritate the stomach causing ulcers or cancer There are different types of ulcers; most common are atrophy, metaplasia, and peptic and gastric ulcer, which appeared to damage the inner lining of the stomach. Furthermore, H. pylori infection is one of the most important risk factors for the development of stomach adenocarcinoma. Peptic ulcers develop due to an imbalance between aggressive factors and protective factors [3]. The virulence of the bacterial strains, environmental variables, and the genetic traits and lifestyles of the hosts all influence the clinical consequences of Helicobacter pylori infections. Certain foods or stress were considered to be the cause for peptic ulcer, however after the discovery of H. pylori [4].

Ulcers are not only the problems associated with $H$. pylori. Peptic ulcers can block the passage of food through the digestive tract, which causes vomiting and swelling from inflammation. Urease is the most important enzyme produced by the $H$. pylori, since it enables survival of the organism in a low $\mathrm{pH}$ environment and also aids colonization in the mucosal membrane of the stomach. The enzymes catalyze the degradation of urea to ammonia and carbon dioxide. Ammonia alkalizes the environment, leading to the neutralization of the acid fluid in the stomach, which allows bacterial survival. Urease was the first virulence factor of $H$. pylori used for diagnostic purposes in gastric pathology [5]. Medicinal plants and algae have achieved their therapeutic properties from their capability to produce renewable and various secondary metabolites which are known as phytochemical constituents. Algae used these phytochemicals as a protection mechanism against pathogen, and those algae are specific protein fragments, and this protein is an essential component required to repair cells, and also algal peptides have less toxicity and more antibacterial properties [6,7]. Numerous species of algae are reported to be rich in proteins, carbohydrates, and bioactive compounds. Bioactive compounds isolated from algal peptides are showing anti-cancer activity and preliminary anti-COVID-19 $[8,9]$.

In the previous research Cbf-K16, a cathelicidin-like antimicrobial peptide, demonstrated wide antibacterial action which is followed Cbf-K16 was found to have effective antibacterial and anti-inflammatory properties, as well as down regulating the expression of adhesion- and cytotoxin-related genes in drug-resistant H. pylori, making it a promising anti-infective therapy option [10]. Sun et al. have recently reported that anti-adhesive peptide which is derived from wheat germ protein is effectively inhibited $H$. pylori adhesion to gastric epithelial cells [11]. The aim of this study was to investigate the antagonistic interaction pattern between the potential 8 algal peptides against the virulence factors of $H$. pylori through in silico analysis intended to treat peptic ulcer and prevent the further complication such as cancer. 


\section{Materials and Methods}

\section{Collections of Virulence Genes H. pylori}

Literature studies reported about the $H$. pylori and also its virulence genes. Commonly there are several genes that have been implicated in disease related to H. pylori. Studies show that several virulence factors are thought to be important once contact with the host cell epithelium. The study reported showed that 21 virulence genes of $H$. pylori are the reason behind the ulcerogenesis, and specifically three gene markers CagA, VacA, and HtrA significantly play the role (Table 1).

\section{Collections of Antimicrobial Algal Peptides}

The potent antibacterial, antitumor, and antimicrobial algal peptide sequences (Table 2) were collected. Among the 12 peptides, 8 peptides were selected for the docking studies. Sequences of peptides are (a) peptide 1, VECYGPNRPQF (Chlorella vulgaris); (b) peptide 2, NIPP-1(PGWNQWFL) (Navicula incerta); (c) peptide 3, NIPP-2 (VEVLPAEL) (Navicula incerta); (d) peptide 4, VPGTPKNLDSPR (Porphyra haitanensis); (e) peptide 5, GPDRPKFLGPF (Tetradesmus obliquus); (f) peptide 6, WYGPDRPKFL (Tetradesmus obliquus); (g) peptide 7, SDWDRF (Tetradesmus obliquus); and (h) peptide 8, WPRGYFL (Tetradesmus obliquus). The aspect of peptide structure is an important factor influencing the conformations adapted by protein and large peptides, and the structures of all 8 algal peptides were fabricated using Discovery Studio software (2017 version) (Fig. 1).

\section{Generation of Stable Confirmation of Peptide Through Minimization}

In molecular mechanics simulations, an essential step is first to assign a force field to calculate the potential energy of input molecule. The Discovery Studio client uses a CHARMm-style residue topology file (RTF) to implement force field calculation. Additionally, each of the supported force fields may include some residue patches to allow variations of the residues. To make stable molecules, energy minimization is performed on structures before docking analysis; it relaxes the conformation and removes the steric overlap that produces bad contacts [24]. In the minimization algorithm, max steps are 2000, RMS gradient is 0.01, and the energy change is 0.0 . In advanced, partial charge estimation is Momany-Rone fixed in the parameter window. Minimized molecules were subjected to the libdock protocol.

\section{LIB Docking}

Libdock is an algorithm for docking small molecules into an active receptor site. Initially, a hotspot map is calculated for the receptor active site which contains polar and a polar group. This hotspot map is subsequently used to rigidly align the ligand conformation to form favorable interactions [25]. In the protocol window, virulence factors are submitted in the input receptor column, and in the ligand column, all 8 minimized peptides are uploaded. The binding spot is chosen based on the receptor cavity in the coordinates of $-5.05467(\mathrm{X}), 60.4518(\mathrm{Y})$, and $-24.6123(\mathrm{Z})$ with the radius of $10.9 \AA$. Other docking preferences, conformation method, minimization algorithm, and advanced options are mentioned in Table 3. 


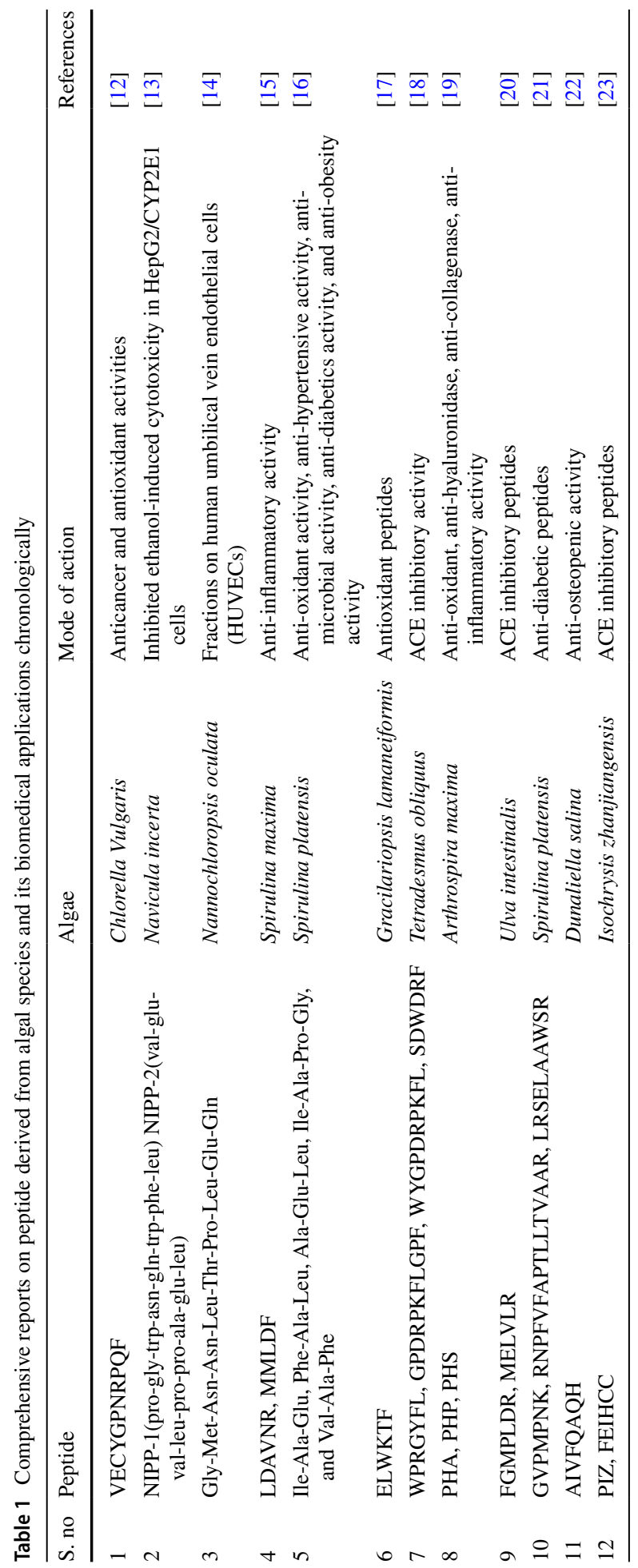


Table 2 Summary of virulence factor available in $H$. pylori and its pathogenicity

\begin{tabular}{|c|c|c|c|c|}
\hline $\begin{array}{l}\text { Virulence } \\
\text { factor }\end{array}$ & Molecular structure & Mechanism in pathogenicity & Effects and causes & References \\
\hline CagA & & $\begin{array}{l}\text { Exogenous cancer-promoting gene } \\
\text { - Type } 4 \text { secretion system } \\
\text { - Phosphorylation of tyrosine. } \\
\text { Cytotoxicity-associated immunodominant } \\
\text { antigen }\end{array}$ & $\begin{array}{l}\text { - Causes cell proliferation } \\
\text { and cell elongation }\end{array}$ & [24] \\
\hline VacA & & 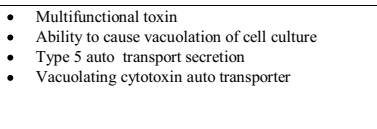 & $\begin{array}{l}\text { - Causes cell vacuolation } \\
\text { and cell necrosis. } \\
\text { - Enhances the activation } \\
\text { of autophagy and } \\
\text { increased cell death in } \\
\text { ER. }\end{array}$ & \\
\hline HtrA & $8 \frac{8}{6}$ & $\begin{array}{l}\text { - H. pylori can secrete proteases. } \\
\text { All clinical } H \text {. pylori separate possess htrA gene } \\
\text { factor and suppression of HtrA proteolytic } \\
\text { activity is adequate to kill } H \text {. pylori. } \\
\text { - Disruption of junction proteins is especially vital } \\
\text { for } H \text {. pylori to take advantage of the host } \\
\text { receptors. } \\
\text { - Periplasmic serine endoprotease DegP }\end{array}$ & $\begin{array}{l}\text { Induce the expression of } \\
\text { host proteases to cleave } \\
\text { extracellular matrix and } \\
\text { intracellular junction } \\
\text { proteins. } \\
\text { Cleaves the E-cadherin } \\
\text { and degrades misfolded } \\
\text { proteins }\end{array}$ & [25] \\
\hline
\end{tabular}
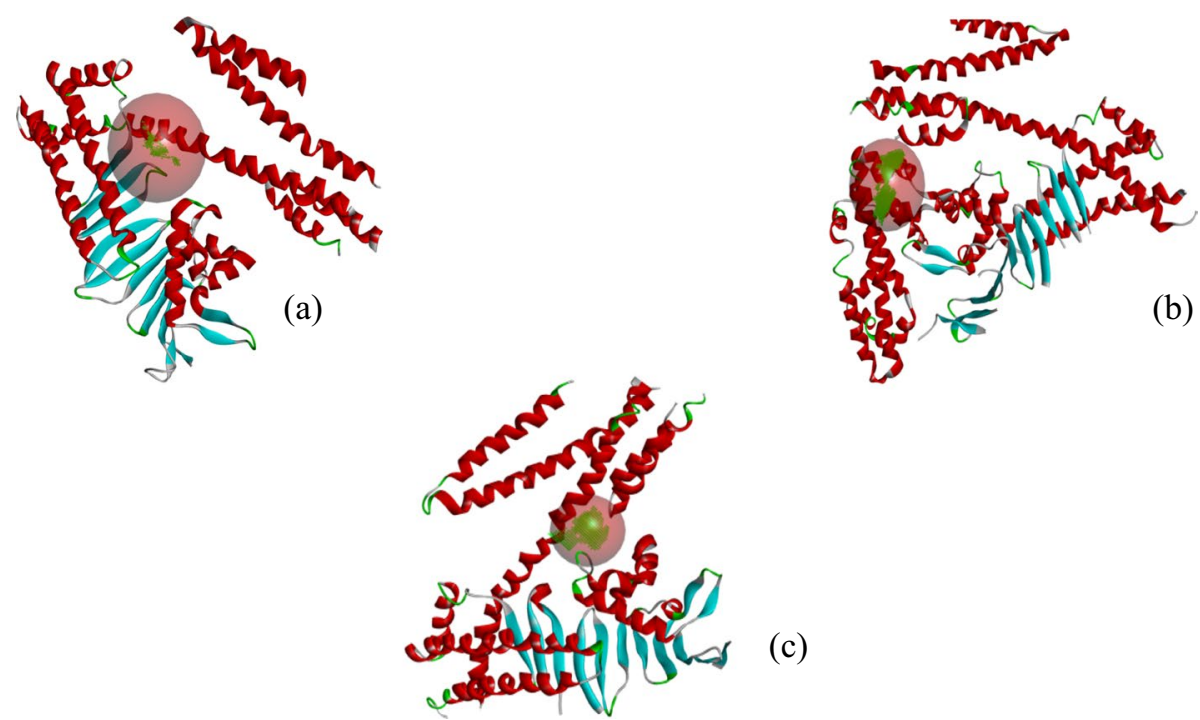

Fig. 1 Secondary structure of the virulence protein CagA (a), VacA (b), and HtrA (c) with the binding site

\section{Results and Discussions}

The three main reasons for the selection of these particular virulence markers are as follows: first, CagA (cytotoxin associated gene) is a cancer-promoting gene. It causes cell proliferation and cell elongation. Second, VacA (Vacuolating cytotoxin gene) is a multifunctional toxin, and it causes cell vacuolation. The last is HtrA-suppression of HtrA proteolytic activity is sufficient to kill $\mathrm{H}$. pylori. These three proteins were collected from their genes CagA, VacA, and HtrA, respectively, and downloaded from protein databases based on their residues length, classification, and resolution values. 
Table 3 Libdock protocol parameter setup

\begin{tabular}{lllll}
\hline Docking preferences & & & Minimization algorithm \\
\cline { 1 - 1 } \cline { 4 - 5 } Max hits to save & & & RMSD cutoff & 1.0 \\
\hline Max number of hits & 100 & & Minimization max steps & 1000 \\
Minimum libdock score & 100 & & Minimization RMS gradient & 0.001 \\
Final score cutoff & 0.5 & & Minimization energy change & 0.0 \\
Max BFGS steps & 50 & & Minimization force field & CHARMm \\
Max conformation hits & 30 & & Implicit solvent model & Distance-dielectrics \\
Max start conformations & 1000 & & Dielectric constant & 1 \\
Steric fraction & 0.10 & & Solvent dielectric constant & 80 \\
Final cluster radius & 0.5 & & Minimum hydrogen radius & 0.8 \\
A polar SASA cutoff & 15.0 & & Non-polar surface constant & 0.92 \\
Polar SASA cutoff & 5.0 & & Non-polar surface coefficient & 0.00542 \\
Surface grid steps & 18 & Salt concentration & 0.0 \\
Conformation method & FAST & Input atomic radii & Van der Waals radii \\
Maximum conformations & 50 & True & Nonbond list radius & 13.0 \\
Discard conformations & 20.0 & Nonbond higher cutoff & 12.0 \\
Energy threshold & & & & 9.0 \\
\hline
\end{tabular}

\section{Minimization}

Energy minimization step for ligands and proteins before docking. Some proteins have less energy value with only in its minimized. Molecular mechanics mainly depend upon threeparameter force field, parameter sets, and minimizing algorithms. The potential energy of the molecules in molecular mechanics is calculated by using force field concepts. A force field is a set of functions and constants used to describe the potential energy of a molecule.

The parameter set includes atomic mass, Vander Waal's radii, bond length, bond angle, the dihedral angle which defines a reference point, and force constants allowing for the calculation of potential energy caused due to the inclusion of attractive or repulsive interactions between atoms. Algorithms to calculate new geometrical positions are so-called minimizers or optimizers [26]. Force field applied three virulence factors, and the 8 peptides were minimized by the smart minimizer (steepest descent 1000 steps + conjugated gradient 1000 steps). It resulted the stable conformers of VacA, HtrA, and CagA with the local energy level of $-46,328.26,33,085.043$, and $-27,465.8 \mathrm{kcal} / \mathrm{mol}$, respectively (Tables 4, 5 and 6).

Similarly the peptide energy was minimized from the range -295.572 to $16,358.4 \mathrm{kcal} /$ mol to -295.572 to $-992.423 \mathrm{kcal} / \mathrm{mol}$. The binding pocked for peptide was selected based on the eraser algorithm, which find the cavities. For vacA XYZ coordinates fixed as a $-5.0546,60.4518$, and -10.9000 with the radius of $9.1000 \AA$. Similarly, the coordinates for HtrA and cagA were found to be $-39.7488,45.4658$, and 4.9687 and $-21.5038,-25.3823$, and -37.6440 , respectively (Fig. 2). 


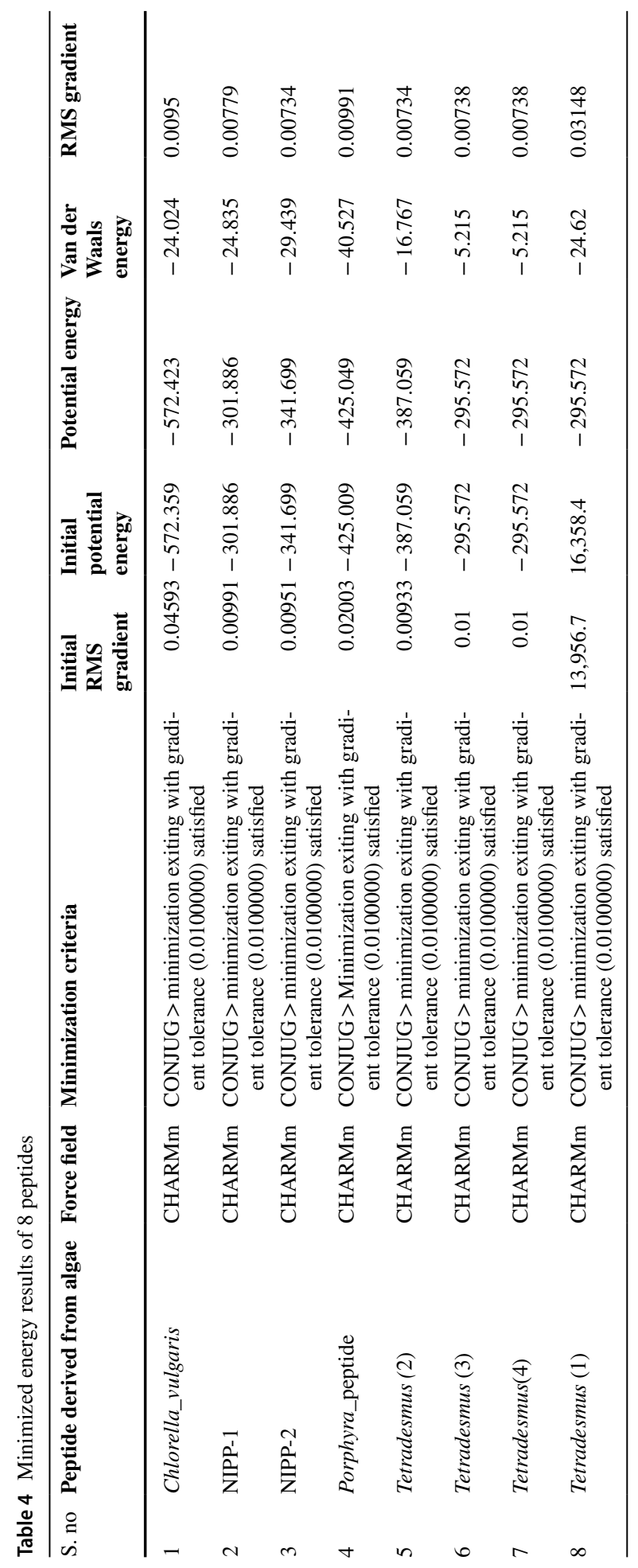




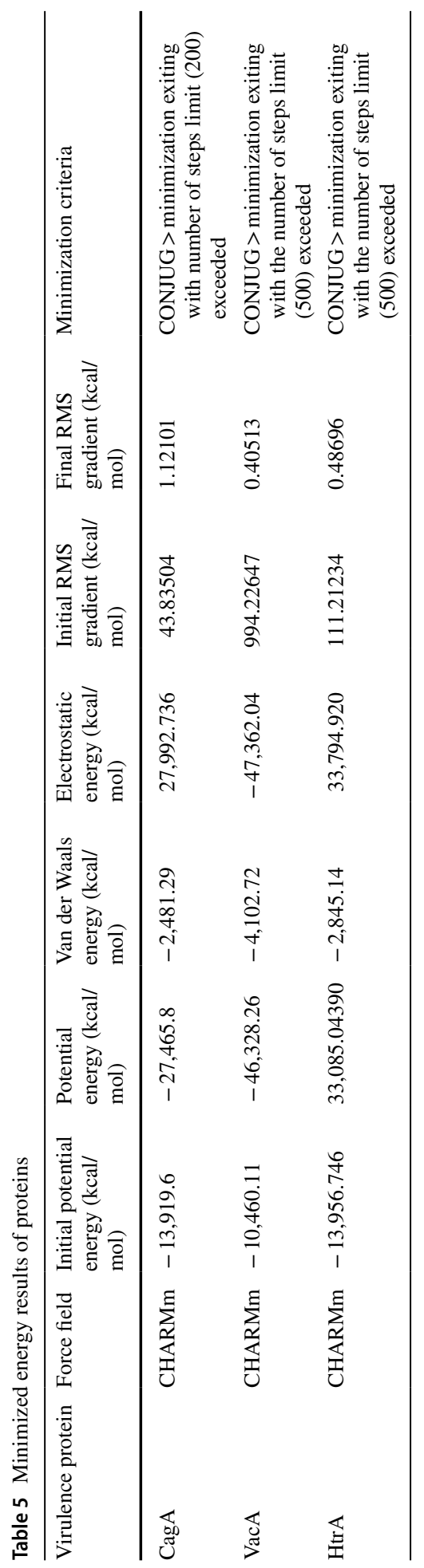


Table 6 Libdock score for the peptide and virulence factor complex

\begin{tabular}{llll}
\hline Peptide name & \multicolumn{2}{l}{ Virulence factor } & \\
\cline { 2 - 4 } & VacA & HtrA & CagA \\
& Libdock score & & \\
\hline Chlorella_vulgaris & $\mathrm{N}$ & $\mathrm{N}$ & $\mathrm{N}$ \\
NIPP-1 & 134.878 & $\mathrm{~N}$ & $\mathrm{~N}$ \\
NIPP-2 & 125.310 & $\mathrm{~N}$ & $\mathrm{~N}$ \\
Porphyra_peptide & $\mathrm{N}$ & $\mathrm{N}$ & $\mathrm{N}$ \\
Tetradesmus (2) & 140.739 & $\mathrm{~N}$ & 166.954 \\
Tetradesmus (3) & 158.603 & 89.397 & 175.625 \\
Tetradesmus (4) & $\mathrm{N}$ & $\mathrm{N}$ & $\mathrm{N}$ \\
Tetradesmus (1) & 140.112 & $\mathrm{~N}$ & $\mathrm{~N}$ \\
\hline
\end{tabular}

$* N$ no conformation dock, $D$ dock, energy indicated in $\mathrm{kcal} / \mathrm{mol}$

\begin{tabular}{|c|c|c|c|c|c|}
\hline $\begin{array}{c}\text { Secondary } \\
\text { structure of } \\
\text { the protein } \\
\text { with } \\
\text { Tetradesmus }\end{array}$ \\
(3) peptide
\end{tabular}

Fig. 2 Secondary structure of the protein CagA, VacA, and HtrA with Tetradesmus (3) peptide using LIBDocking

\section{Docking Pattern Examination}

\section{$\operatorname{vac} A$}

The docking algorithm run between the vacA virulence factor and 8 peptides results illustrated that, totally 222 conformers generated, 81 poses docked and 2 molecules failed to dock. The failing of the legends due to the clashes of active site amino acids with the amino acids of peptide. Figure 3 shows that the highest binding molecule Tetradesmus (3) formed 17 hydrogen bonds and 3 attractive charges that made the molecule bind with highest energy of $158.603 \mathrm{k} \mathrm{cal} / \mathrm{mol}$ compared to other molecules. 


\begin{tabular}{|c|c|c|c|}
\hline & CagA & VacA & HtrA \\
\hline $\begin{array}{l}\text { Interactions of active } \\
\text { amino acids with } \\
\text { Tetradesmus (3) } \\
\text { peptide (3D view) }\end{array}$ & $\frac{4}{x-2 x}$ & 作 & $y=$ \\
\hline $\begin{array}{l}\text { Interactions of active } \\
\text { amino acids with } \\
\text { Tetradesmus (3) } \\
\text { peptide (2D view) }\end{array}$ & (1597) & (1) & 48 \\
\hline Inference & $\begin{array}{l}\text { There is no unfavourable donor. ILE A: } 675 \text { is } \\
\text { the pi-alkyl group and there are more than two } \\
\text { conventional hydrogen bond they are marked } \\
\text { as green in colour }\end{array}$ & $\begin{array}{l}\text { ARG A:53 is the unfavourable donor donor } \\
\text { and ALA A:42, SER A:43, ILE A: } 35 \text { are the } \\
\text { conventional hydrogen bond }\end{array}$ & $\begin{array}{l}\text { LYS A:694 and LEU A: } 734 \text { are conventional } \\
\text { hydrogen bond and SER A: } 437 \text { is the } \\
\text { unfavourable donor. There are four attractive } \\
\text { charges. They are: ASP A: } 416 \text {, ASP A: } 690 \text {, LYS } \\
\text { A: } 691 \text {, and LYS A:414. }\end{array}$ \\
\hline
\end{tabular}

Fig. 3 Interactions of active amino acids of CagA (a, d), Vac (b, e), and Htr (c, f) with Tetradesmus (3) peptide

\section{HtrA}

Libdock protocol run result of HtrA and 8 peptides showed that the only 1 peptide docked well and other possess are failed and totally 222 conformers generated. The interaction analysis shown in the figure explicates the interaction of docked Tetradesmus (3) peptide with HtrA. Five salt bridges, two hydrogen bonds, two $\pi$-alkyls, and one $\pi-\sigma$ bond network were formed. Among the 8, Tetradesmus (3) only showed better inhibition with the energy of $89.397 \mathrm{kcal} / \mathrm{mol}$.

\section{CagA}

Only two ligands docked and 35 conformers generated in the CagA libdock with peptides. Tetradesmus (3) and (2) only formed bonding with the CagA. Specifically, Tetradesmus (3) formed around $8 \mathrm{H}$-bonds, one $\pi$-alkyl, and $\pi$-cationic interaction that made the molecule fit proper orientation inside the binding pocket of CagA. The binding energy was found to be $175.625 \mathrm{kcal} / \mathrm{mol}$ (Table 7).

In silico molecular modeling studies will lead to generation of a potent molecule in less time with reduction in the usage of chemicals and animals and also reduce the expenses. Owing to its invasiveness and pathogenicity, numerous treatment and control methods were employed to target the $H$. pylori $[27,28]$. Hence, to develop the vaccine against the pathogen is the significant task and at the same time the discovery and development of antibiotic among the most powerful and successful achievements of modern science and technology for the control of infectious diseases. Prolonged usage of broad spectrum antibiotics leads to the emergence of drug resistance. Apart from that, the algae have achieved their therapeutic properties from their capability to produce renewable and various secondary metabolites which are known as phytochemical constituents, and these phytochemicals were used as a protection mechanism against pathogen. 


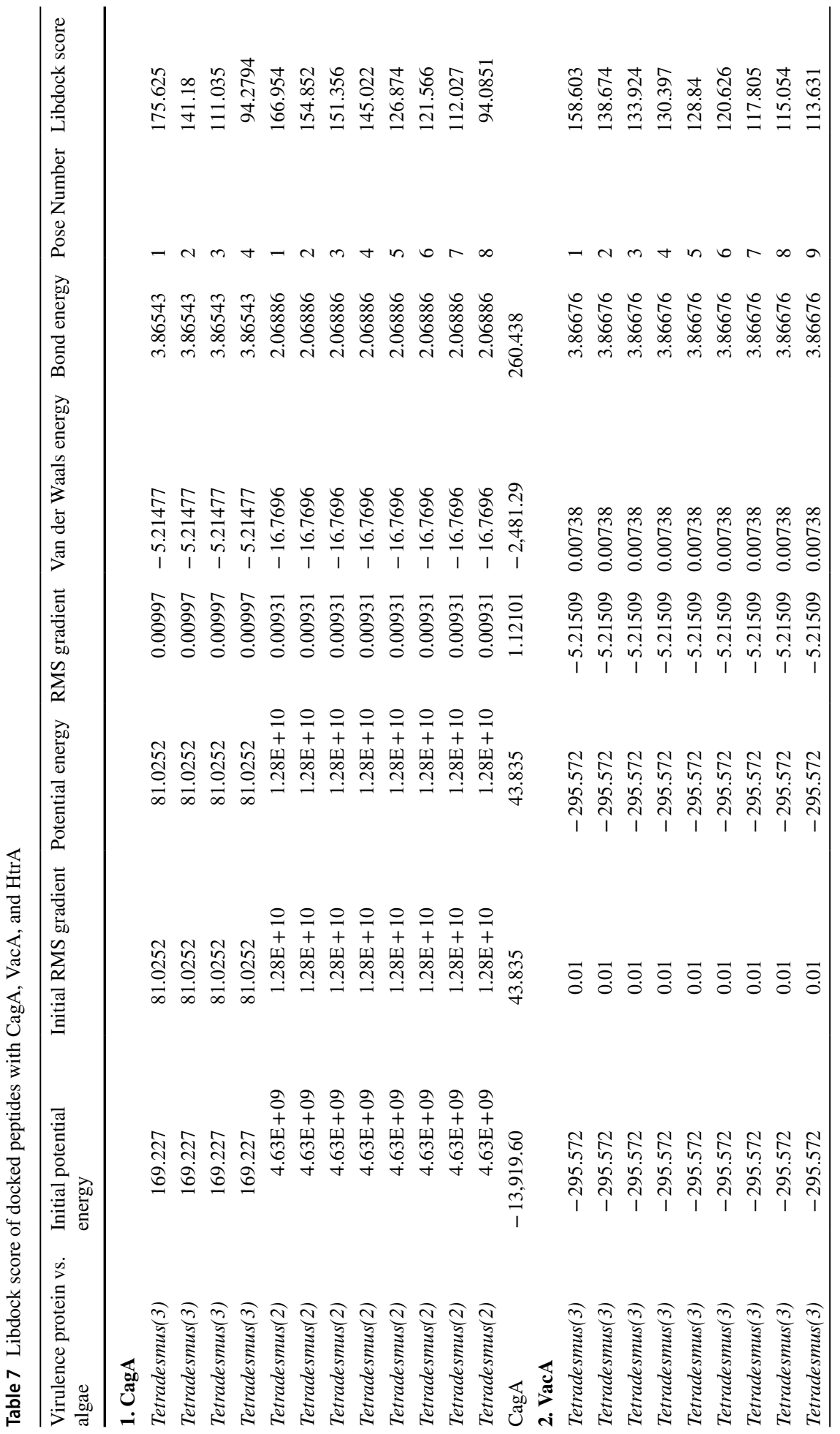




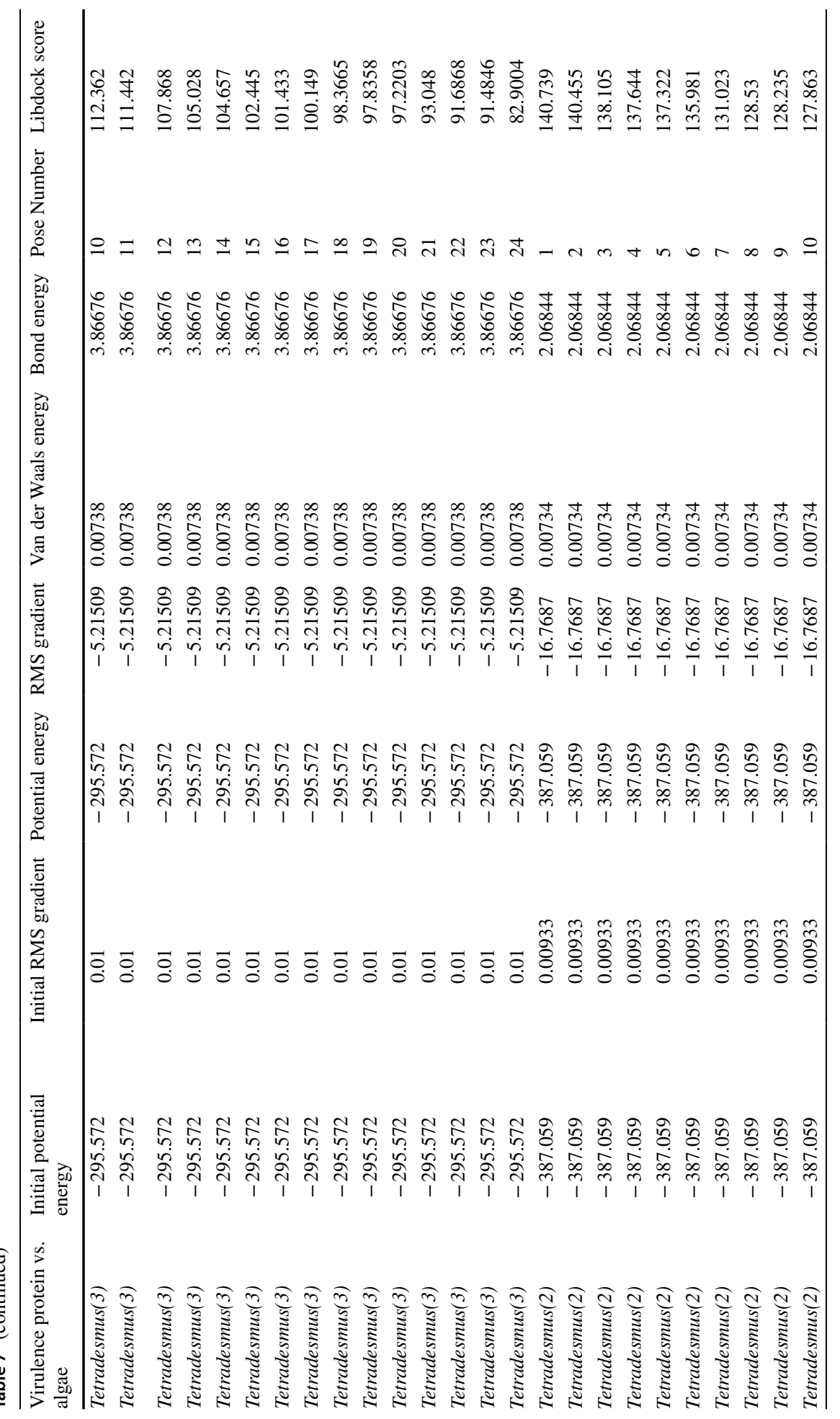




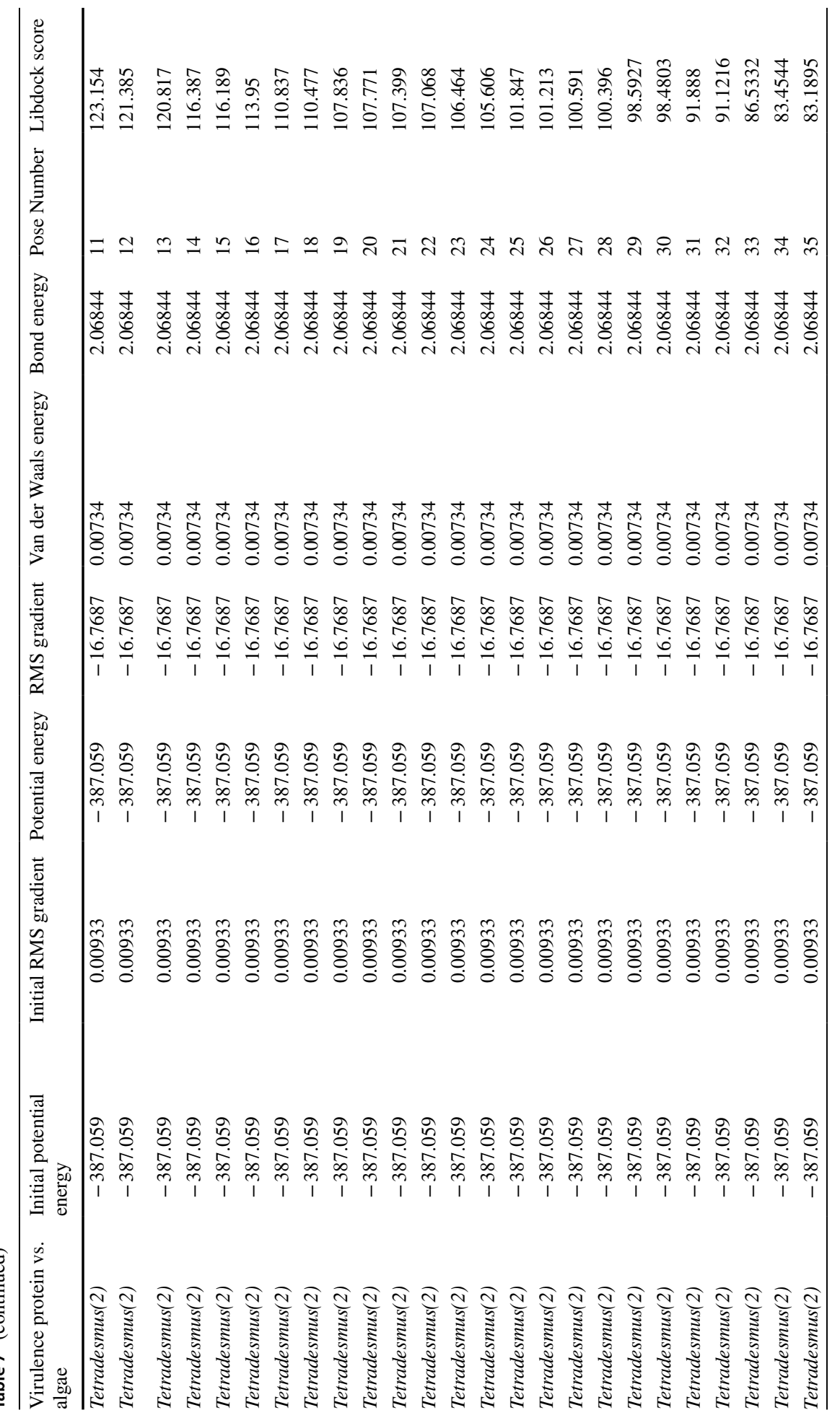




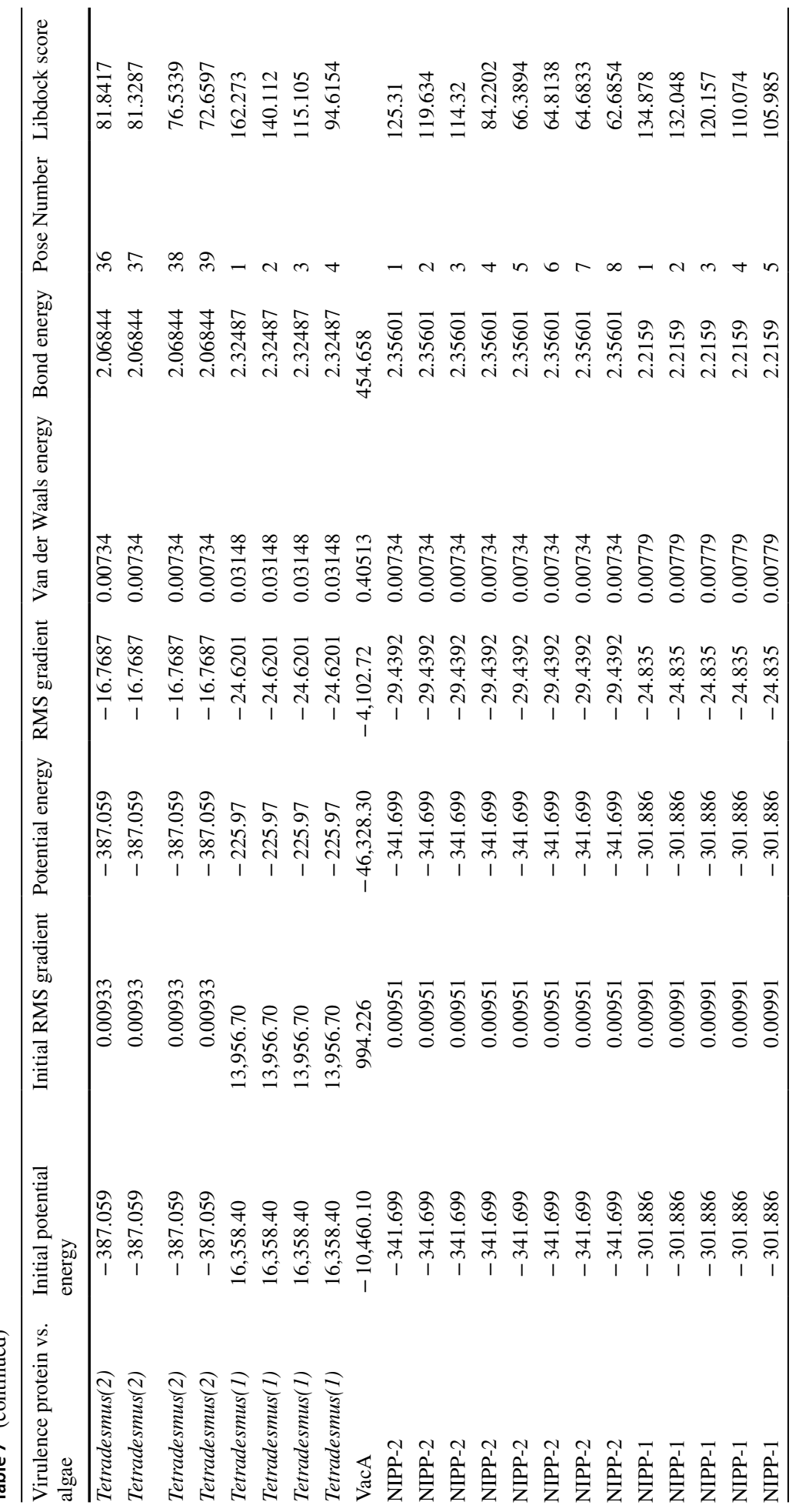




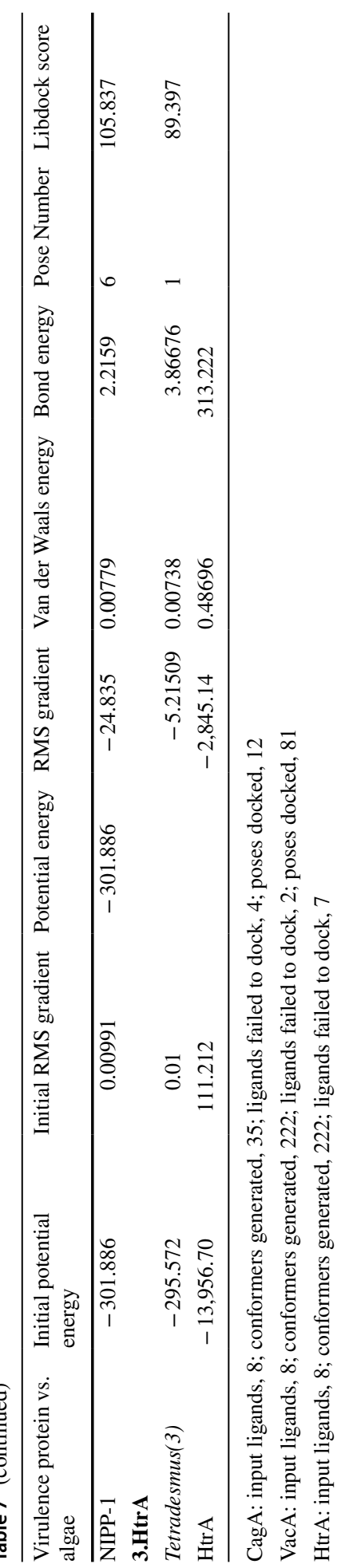




\section{Conclusion}

There is a tremendous need for novel antimicrobial agents from different microbes in general and microalgae in particular provides important sources of chemical compounds and secondary metabolites which have many therapeutic applications. In this study, microalgal peptide derived from Tetradesmus sp. exhibited as antibacterial and inhibitor of $H$. pylori. It almost acts on all the three selected virulence factors, VacA, CagA, and HtrA through antagonizing effect. These peptides could be lead molecules to treat the $H$. pylori-induced diseases as well as to develop a vaccine.

Acknowledgements DM is thankful to the SEED/AUN-NET JICA through Special Program on Research Against Corona (SPRAC 2020) program. DM and RS are thankful to BSACIST funded through Crescent Seed Money (CSD/CSM/3 dated 11/03/2021).

Author Contribution DM: Corresponding author, guidance, and data analysis. TA: Data acquisition and manuscript writing. RS: Data analysis. NI: Data analysis.

Data Availability Not applicable.

\section{Declarations}

Ethics Approval Not applicable.

Consent to Participate Not applicable.

Consent for Publication Not applicable.

Conflict of Interest The authors declare no competing interests.

\section{References}

1. de Lima Silva, L. L., Oliveira, A. K. S., Gama, A., \& Barbosa, M. S. (2021). Helicobacter pylori virulence dupA gene: Risk factor or protective factor. Brazilian Journal of Microbiology. https://doi.org/10.1007/ s42770-021-00553-9

2. Ishaq, S., \& Nunn, L. (2015). Helicobacter pylori and gastric cancer: A state of the art review. Gastroenterology and hepatology from bed to bench, 8(Suppl1), S6-S14.

3. Lanas, A., \& Chan, F. K. (2017). Peptic ulcer disease. The Lancet, 390(10094), 613-624. https://doi.org/10. 1016/S0140-6736(09)60938-7

4. Majumdar, D., Bebb, J., \& Atherton, J. (2011). Helicobacter pylori infection and peptic ulcers. Medicine, 39(3), $154-161$.

5. Chen, M. F., Zhang, Y. Y., Di He, M., Li, C. Y., Zhou, C. X., Hong, P. Z., \& Qian, Z. J. (2019). Antioxidant peptide purified from enzymatic hydrolysates of Isochrysis Zhanjiangensis and its protective effect against ethanol induced oxidative stress of HepG2 cells. Biotechnology and Bioprocess Engineering, 24(2), 308-317.

6. Bertleff, M. J., \& Lange, J. F. (2010). Perforated peptic ulcer disease: A review of history and treatment. Digestive surgery, 27(3), 161-169. https://doi.org/10.1159/000264653

7. Sathya, R., MubarakAli, D., MohammedSaalis, J., \& Jung-Wan, K. (2021). Systemic review on the production of microalgal peptides: Bioprocess and applications. Sustainability., 13, 3262. https://doi.org/10.3390/su130 63262

8. Abu-Ghannam, N., \& Rajauria, G. (2013). Antimicrobial activity of compounds isolated from algae. In Functional ingredients from algae for foods and nutraceuticals, 287-306. Wood head Publishing. https://doi.org/ 10.1533/9780857098689.2.287

9. MubarakAli, D., MohammedSaalis, J., Sathya, R., Irfan, N., Kim, J-W. (2021). An investigation of microalgal peptides against spike protein of COVID19: An in silico approach. Microbial Pathogenesis, 160, 105189 
10. Guedes, A. C., Amaro, H. M., \& Malcata, F. X. (2011). Microalgae as sources of high added-value compounds-A brief review of recent work. Biotechnology progress, 27(3), 597-613. https://doi.org/10.1002/btpr. 575

11. Jiang, M., Ma, L., Huang, Y., Wu, H., Dou, J., \& Zhou, C. (2020). Antimicrobial activities of peptide CbfK16 against drug-resistant Helicobacter pylori infection in vitro and in vivo. Microbial pathogenesis, 138, 103847.

12. Sun, X., Zhang, S., Udenigwe, C. C., Ren, J., Li, S., Wang, H., \& Liu, X. (2020). Wheat germ-derived peptides exert anti-adhesive activity against Helicobacter pylori: Insights into structural characteristics of identified peptides. Journal of Agricultural and Food Chemistry, 68(43), 11954-11974.

13. Sheih, I. C., Fang, T. J., Wu, T. K., \& Lin, P. H. (2010). Anticancer and antioxidant activities of the peptide fraction from algae protein waste. Journal of Agricultural and Food Chemistry, 58(2), 1202-1207.

14. Kang, K. H., Qian, Z. J., Ryu, B., Kim, D., \& Kim, S. K. (2012). Protective effects of protein hydrolysate from marine microalgae Navicula incerta on ethanol-induced toxicity in HepG2/CYP2E1 cells. Food Chemistry, 132(2), 677-685. https://doi.org/10.1016/j.foodchem.2011.10.031

15. Yu, J., Hu, Y., Xue, M., Dun, Y., Li, S., Peng, N., \& Zhao, S. (2016). Purification and identification of antioxidant peptides from enzymatic hydrolysate of Spirulina platensis. Journal of Microbiology and Biotechnology, 26(7), 1216-1223. https://doi.org/10.4014/jmb.1601.01033

16. Vo, T. S., Ryu, B. M., \& Kim, Sk. (2013). Marine-derived polysaccharides for regulation of allergic responses. Journal of Functional Foods, 5(3), 1336-1346.

17. Yücetepe, A \& Ozçelik, B. (2016). Bioactive peptides isolated from microalgae spirulina platensis and their biofunctional activities. Academic Food Journal, 14(4), 1-10.

18. Zhang, X., Cao, D., Sun, X., Sun, S., \& Xu, N. (2019). Preparation and identification of antioxidant peptides from protein hydrolysate of marine alga Gracilariopsis lemaneiformis. Journal of Applied Phycology, 31(4), 2585-2596.

19. Montone, C. M., Capriotti, A. L., Cavaliere, C., La Barbera, G., Piovesana, S., Chiozzi, R. Z., \& Laganà, A. (2018). Peptidomic strategy for purification and identification of potential ACE-inhibitory and antioxidant peptides in Tetradesmus obliquus microalgae. Analytical and Bioanalytical Chemistry, 410(15), 3573-3586.

20. Montalvo, G. E. B., Thomaz-Soccol, V., Vandenberghe, L. P., Carvalho, J. C., Faulds, C. B., Bertrand, E., \& Soccol, C. R. (2019). Arthrospira maxima OF15 biomass cultivation at laboratory and pilot scale from sugarcane vinasse for potential biological new peptides production. Bioresource technology, 273, 103-113.

21. Sun, S., Xu, X., Sun, X., Zhang, X., Chen, X., \& Xu, N. (2019). Preparation and identification of ACE inhibitory peptides from the marine macroalga Ulva intestinalis. Marine drugs, 17(3), 179.

22. Hu, S., Fan, X., Qi, P., \& Zhang, X. (2019). Identification of anti-diabetes peptides from Spirulina platensis. Journal of functional foods, 56, 333-341.

23. Xia, E., Zhai, L., Huang, Z., Liang, H., Yang, H., Song, G., \& Tang, H. (2019). Optimization and identification of antioxidant peptide from underutilized Dunaliella salina protein: Extraction, in vitro gastrointestinal digestion, and fractionation. BioMed research international, 2019.

24. Venkatachalam, C. M., Jiang, X., Oldfield, T., \& Waldman, M. (2003). LigandFit: A novel method for the shape-directed rapid docking of ligands to protein active sites. Journal of Molecular Graphics and Modelling, 21(4), 289-307. https://doi.org/10.1016/S1093-3263(02)00164-X

25. Leach, A. R., Shoichet, B. K., \& Peishoff, C. E. (2006). Prediction of protein- ligand interactions Docking and scoring: successes and gaps. Journal of medicinal chemistry, 49(20), 5851-5855. https://doi.org/10.1021/ jm060999m

26. Jain, A. N. (1996). Scoring non-covalent protein-ligand interactions: A continuous differentiable function tuned to compute binding affinities. Journal of computer-aided molecular design, 10(5), 427-440.

27. Maeda, S., Ogura, K., Yoshida, H., Kanai, F., Ikenoue, T., Kato, N., \& Omata, M. (1998). Major virulence factors, VacA and CagA, are commonly positive in Helicobacter pylori isolates in Japan. Gut, 42(3), 338343. https://doi.org/10.1136/gut.42.3.338

28. Zarzecka, U., Modrak-Wójcik, A., Figaj, D., Apanowicz, M., Lesner, A., Bzowska, A., \& Skorko-Glonek, J. (2019). Properties of the HtrA protease from bacterium Helicobacter pylori whose activity is indispensable for growth under stress conditions. Frontiers in Microbiology, 10, 961. https://doi.org/10.3389/fmicb.2019. 00961

Publisher's Note Springer Nature remains neutral with regard to jurisdictional claims in published maps and institutional affiliations. 